\title{
Estratégias de securitização no setor de construção civil: determinantes e impactos no desempenho econômico-financeiro
}

A forma como as empresas definem sua estrutura de capital traz impactos para o seu desempenho financeiro. Dentre as possibilidades para financiamento se encontra a securitização, que embora seja um tema discutido no meio acadêmico, pouca atenção tem sido dada para sua relação com o desempenho empresaria (RIACHI et al., 2015). No Brasil, um dos setores que mais fazem uso deste tipo de instrumento é o setor de construção civil. Desta forma, este trabalho teve por objetivo analisar os determinantes das estratégias de securitização utilizadas pelas empresas do setor de construção civil e os impactos no seu desempenho econômico e financeiro. A pesquisa utilizou uma abordagem quantitativa e fez uso do método descritivo, a amostra foi composta por 15 empresas do setor, 0 estudo abordou o período de 2007 a 2015 e foi realizado com a utilização da técnica de análise de regressão com dados em painel balanceado. A principal variável explicativa determinante do nível de securitização foi o custo da dívida, reforçando a hipótese de que empresas com maior custo de dívida tendem utilizar de forma mais intensa a securitização. Já em relação ao desempenho, foi constatado que o nível de securitização influencia o indicador Preço/Lucro, desta maneira, esta estratégia pode contribuir para a criação de valor.

\section{Strategies of securitization in the construction sector: determinants and impacts on economic and financial performance}

\begin{abstract}
The way of companies define their capital structure impacts their financial performance. Among the possibilities for financing, there is securitization, which although it is a topic discussed in the academic environment; little attention has been given to its relationship with business performance (RIACHI et al., 2015). In Brazil, one of the sectors that most use this type of instrument is the civil construction sector. Thus, this work aimed to analyze the determinants of securitization strategies used by companies in the civil construction sector and the impacts on their economic and financial performance. The research used a quantitative approach and made use of the descriptive method, the sample was composed of 15 companies in the sector, the study covered the period from 2007 to 2015 and was carried out using the technique of regression analysis with balanced panel data. The main explanatory variable that determines the level of securitization was the cost of debt, reinforcing the hypothesis that companies with a higher cost of debt tend to use securitization more intensively. Regarding performance, it was found that the level of securitization influences the Price/Profit indicator, so this strategy can contribute to the creation of value.
\end{abstract}

Keywords: Financing Strategies; Business performance; Construction

Topic: Finanças Empresariais

Reviewed anonymously in the process of blind peer
Received: 08/10/2020

Approved: $22 / 12 / 2020$
Tiago César Farinelli (iD

Universidade de São Paulo, Brasil

http://lattes.cnpq.br/1184525386556869

http://orcid.org/0000-0003-4875-957X

t1ago cesar@yahoo.com.br

David Ferreira Lopes Santos (it)

Universidade Estadual Paulista Júlio de Mesquita Filho, Brasil

http://lattes.cnpq.br/5017639694729451

http://orcid.org/0000-0003-3890-6417

david.lopes@unesp.br
Referencing this:

FARINELLI, T. C.; SANTOS, D. F. L.. Estratégias de securitização no setor de construção civil: determinantes e impactos no desempenho econômico-financeiro. Revista Brasileira de Administração Científica, v.11, n.4, p.10-26, 2020. DOI: http://doi.org/10.6008/CBPC2179$\underline{684 X .2020 .004 .0002}$ 


\section{INTRODUÇÃO}

O estudo sobre as fontes de financiamento para as firmas é considerado um dos temas centrais das finanças corporativas (FAMÁ et al., 2000; CORREA et al., 2013; KUDLAWICZ et al., 2015). A forma como as empresas captam recursos é um fator de extrema importância para as estratégias empresariais que visam à minimização do custo de capital (KUDLAWICZ et al., 2015).

Foi com Modigliani et al. (1958), ao afirmarem que a estrutura de capital não interfere no valor da empresa, que o tema de estrutura de capital começou a ser discutido teoricamente. Desde então, diversas teorias foram construídas ampliando a discussão sobre o assunto. Famá et al. (2000) trazem destaque ao trabalho de Jensen et al. (1976), que introduziram a questão do conflito de agência, e ao trabalho de Ross (1977), que discutiu a influência da política de dividendos das empresas.

Correa et al. (2013) assinalam que a duas correntes teóricas principais no tema em contraponto à irrelevância de Modigliani et al. (1958) são a pecking order e a trade-off, que são derivadas dos trabalhos de Jensen et al. (1976) e Ross (1977). A teoria de pecking order diz que as empresas seguem uma hierarquia na busca de recursos para o financiamento de suas operações, dando preferência para a retenção dos lucros gerados, depois utilizando o endividamento, e como última opção a emissão de ações, já para a teoria de trade-off, existe uma estrutura de capital meta para as empresas, que traria o equilíbrio ideal entre os benefícios e os custos consequentes do endividamento (CORREA et al., 2013; ASSIS et al., 2016).

Essas correntes contrapõem a proposição de Modigliani et al. (1958), já que indicam que a estrutura de capital interfere no valor da empresa. Levando em conta esta constatação, a forma como as empresas utilizam a alavancagem pode contribuir para o seu desempenho financeiro e econômico (KUDLAWICZ et al., 2015; COSTA, 2017). Assim é imprescindível que as empresas façam uso de estratégias para seu endividamento visando à utilização de instrumentos financeiros que viabilizem suas operações e novos investimentos (KUNDAKCHYAN et al., 2014).

Neste sentido, a securitização tem ganhado espaço dentro das economias de mercado, sendo uma alternativa de financiamento, este instrumento converte ativos em títulos que são negociados no mercado de capitais, com isso possibilita uma melhora na disponibilidade de crédito (MPUNDU et al., 2013).

Riachi et al. (2015) dizem que o processo de securitização, por parte das empresas, consiste em um conjunto de ativos, normalmente uma carteira de recebíveis, que são cedidos para uma Sociedade de Propósito Específico (SPE), que por sua vez faz uso destes ativos como garantia para títulos que são emitidos e ficam disponíveis para investidores. Segundo os autores, diferentemente da dívida garantida tradicional, a securitização transfere a propriedade dos ativos para uma organização distinta da empresa de origem (para a SPE), o que faz com que o investidor que adquira os títulos não sofra com o risco de falência da empresa originária.

Segundo Fernandes et al. (2014) a utilização da securitização como instrumento de financiamento tem obtido um significativo aumento no Brasil nos últimos anos, este crescimento ocorreu principalmente a partir de 2001, ano em que houve a regulamentação dos Fundos de Investimentos em Direitos Creditórios 
(FIDCs). Os FIDCs foram constituídos através da Resolução CMN n² 2907, eles são ativos que se caracterizam como direitos creditórios, que são originados de operações nos segmentos financeiro, comercial, industrial, imobiliário e de prestação de serviços (PINHEIRO et al., 2009).

Segundo a Associação Brasileira das Entidades dos Mercados Financeiro e de Capitais (ANBIMA, 2017) as empresas no Brasil captaram 3,6 bilhões de reais no ano de 2016 através dos FIDCs, representando um valor de 2,8\% dentro do mercado de capitais. As empresas do setor de construção civil no Brasil são umas das que têm se aproveitado dos instrumentos de securitização, principalmente para captar recursos de longo prazo visando o financiamento de suas atividades (FARIA, 2011).

Apesar da securitização ser um tema de grande discussão, o seu impacto na política de investimentos e sobre desempenho das empresas tem recebido pouca atenção nas pesquisas acadêmicas (RIACHI et al., 2015). Neste contexto, a questão que motivou a proposição deste estudo é: quais são os determinantes das estratégias de securitização utilizadas pelas empresas do setor de construção civil e qual o impacto no seu desempenho econômico e financeiro?.

Desta maneira, este trabalho tem por objetivo analisar os determinantes das estratégias de securitização utilizadas pelas empresas do setor de construção civil e os impactos no seu desempenho econômico e financeiro. A relevância do tema para este setor deve-se a sua importância para a economia, formação do capital bruto, geração de emprego e renda e arrecadação (FARIA, 2011).

A utilização da securitização proporciona muitos benefícios para as economias, servindo de fonte de financiamento de ativos para as empresas, pois traz acesso direto ao mercado de capitais, e leva mais competitividade ao mercado de crédito, já que serve de alternativa na captação por parte dos bancos menores e reduz o risco, pois este é dividido entre muitos investidores (PINHEIRO et al., 2009).

Desta forma, buscar compreender como as empresas do setor de construção civil utilizam as operações de securitização como fonte de financiamento para suas operações, e quais os impactos destas estratégias em seu desempenho financeiro pode contribuir para um melhor entendimento do tema tanto por acadêmicos quanto por profissionais de mercado.

Para alcançar o objetivo deste estudo, este artigo está organizado em mais quatro seções além desta introdução. A próxima seção apresenta o quadro teórico que abarca o tema e subsidia a construção das variáveis e a análise dos resultados. A terceira seção traz os materiais e métodos que viabilizaram a pesquisa empírica. Os resultados e discussões são apresentados na quarta seção que também apresenta os avanços alcançados. As conclusões e recomendações demonstram as implicações teórica e gerenciais do estudo, assim como novas direções de pesquisa neste tema. As referências utilizadas são listadas no final do texto.

\section{REVISÃO TEÓRICA}

Nesta seção apresenta-se um levantamento bibliográfico sobre o desempenho empresarial e sobre a securitização. Na subseção de desempenho empresarial trata-se principalmente o aspecto financeiro, já na subseção de securitização discute-se as suas principais características e os benefícios e riscos de sua utilização pelas empresas, bem como sua relação com o desempenho. No fim desta seção destaca-se a securitização 
no Brasil principalmente com a utilização dos Fundos de Investimentos em Direitos Creditórios (FIDCs).

\section{Desempenho Empresarial}

A realização de estratégias que possam produzir uma melhora no desempenho pode ser considerada um dos principais objetivos das organizações (STARLING et al., 2014). O estudo sobre o desempenho das empresas, assim como a forma de mensuração, tem papel relevante nas pesquisas da área de finanças (KANGARLOUEI et al., 2012). Estes estudos têm procurado investigar as variáveis que influenciam o desempenho, tanto de empresas privadas quanto públicas (CUTLER, 2011; FERREIRA et al., 2014).

A avaliação do desempenho empresarial é de grande importância para gestores, concorrentes, credores e investidores, tanto atuais quanto potenciais (YALCIN et al., 2012). A obtenção de um desempenho superior, parte do pressuposto que a empresa possui vantagem competitiva, ou seja, ela consegue criar mais valor que seus concorrentes (BRITO et al., 2012). Desta forma, as empresas buscam encontrar fontes que produzam uma vantagem competitiva sustentável (GUNDAY et al., 2011).

O esforço de se alcançar uma posição de vantagem competitiva, faz com que as empresas explorem seus recursos e competências, a fim de possibilitar a realização de estratégias que melhorem seus resultados (MAZZI, 2011).

A análise dos resultados organizacionais é realizada predominantemente através de indicadores econômicos e financeiros, que segundo Matitz et al. (2011) tem sido a forma mais utilizada para operacionalizar o conceito de desempenho. O desempenho empresarial, em seu aspecto financeiro, aborda fatores principalmente relacionados à lucratividade, aumento de receita e crescimento de valor de mercado (STARLING et al., 2014).

A forma como a empresa se financia é um dos fatores que impactam no seu desempenho, com isso a busca de recursos que viabilizam as estratégias de investimentos das firmas, também é vista como essencial para sua competitividade e sobrevivência.

\section{Securitização}

Luxo (2010) diz que foi a partir nos anos 1980 que as empresas nos Estados Unidos começaram a realização de operações estruturadas, assim gerando o lançamento de títulos que representam um conjunto de recebíveis, como empréstimos e financiamentos, em que o risco de crédito não era mais baseado no risco do emissor, mas sim nos fluxos de caixa gerados pelos recebíveis, desta forma se iniciou as operações conhecidas como Asset-Backed Securities (títulos garantidos por ativos).

As operações de securitização, assim como outras inovações financeiras, tiveram um grande crescimento na década de 1990, isso se deve principalmente pela falta de normas que impusessem maior controle, desta forma houve grande crescimento dos ativos financeiros negociados nos mais diversos mercados, inclusive com grande mobilidade de capitais entre os países (SILVESTRINI et al., 2011).

Luxo (2010) diz que a função da securitização é de "converter determinados créditos em lastro para títulos ou valores mobiliários a serem emitidos posteriormente". Silvestrini et al. (2011) definem o conceito 
de securitização como "inovação financeira criada com o objetivo de facilitar e de agilizar o processo de captação de recursos no mercado financeiro". Luxo (2010) ainda diz que a securitização é uma operação financeira estruturada, que tem o objetivo de eliminar ou minimizar o risco de crédito da empresa que emite os títulos mobiliários que são lastreados em ativos.

Na securitização ocorre a transferência de propriedade de ativos de uma empresa para uma SPE, que depois vende créditos para investidores externos, esta transferência de propriedade é a principal característica que diferencia a securitização da dívida garantida tradicional, desta forma o investidor deixa de sofrer com o risco de falência da empresa originaria (AYOTTE et al., 2011).

A securitização traz liquidez aos ativos, assim ficando disponível para potenciais investidores, que poderão posteriormente negociá-los em um mercado secundário, e com isso realizando uma dispersão da propriedade destes ativos (WÓJCIK, 2011). Mpundu et al. (2013) dizem que a securitização possibilita a conversão de ativos que poderiam ser considerados de difícil negociação em títulos que podem ser mais facilmente negociados dentro do mercado de capitais.

As operações de negociações destes títulos funcionam simplesmente com base na expectativa da geração de fluxos de caixa dos ativos que estão lastreados a estes títulos (SILVESTRINI et al., 2011). Assim os investidores ao adquirirem estes títulos, devem se preocupar principalmente com a qualidade destes ativos, em vez de se preocupar com a empresa como um todo (FABOZZI et al., 2007; AYOTTE et al., 2011).

Para Silvestrini et al. (2011) estes instrumentos estruturados podem oferecer aos investidores "um maior retorno, explicado pela ausência da intermediação financeira, no sentido do spread bancário e um menor risco em função das garantias ou da qualidade dos ativos que estejam lastreando esses instrumentos estruturados".

Luxo (2010) diz que um ponto importante a ser considerado é o rating de crédito, como por exemplo, uma empresa que possuir baixa classificação de crédito, e assim com dificuldade de conseguir financiamento com baixo custo, poderá, em uma operação de securitização, utilizar contas a receber de empresas com um rating melhor, desta forma conseguirá recursos a um custo menor, já que o risco para os investidores será a capacidade de pagamento dos devedores (que possuem rating melhor).

Fernandes et al. (2014) dizem que a redução do custo, ao obter recursos com a securitização de ativos, decorre principalmente da diminuição do prêmio pelo risco de falência, já que a SPE poderá ter rating de crédito melhor que a empresa originaria. Com isso, o rating de crédito dos títulos será baseado unicamente na força do conjunto de ativos (FABOZZI et al., 2007).

Pinheiro et al. (2009) dizem que além da redução no custo de captação de recursos, outra possibilidade que a securitização oferece é a redução do nível de envididamento para as empresas, já que a necessidade de financiamento de recursos para investimentos pode ser suprida com a securitização, que segundo Ayotte et al. (2011), esta operação para empresa se caracteriza mais como uma venda de ativo do que um empréstimo garantido. Desta forma os ativos securitizados são removidos dos balanços e o recurso captado fica disponível no caixa da empresa (RIACHI et al., 2015).

Outro benefício que pode ser alcançado com a utilização da securitização é a transferência de risco, 
já que a empresa ao transferir a propriedade dos ativos para a SPE, também passa a não ter mais relação com risco destes ativos (LE et al., 2016). “Nesse processo, há transferência de riscos, pois, quando o título é adquirido, o risco inerente ao ativo é repassado para o investidor que o adquiriu" (SILVESTRINI et al., 2011).

Porém, levando em conta esta transferência de risco, alguns problemas podem existir, já que existe uma assimetria de informação entre a empresa e os investidores, desta forma as empresas podem ter uma conduta inadequada na seleção dos ativos, agindo apenas em prol de seu interesse e indo contra o interesse dos investidores, esta situação é chamada de problema de agência (LE et al., 2016).

Favero Júnior (2014) diz que uma forma de aumentar a segurança para o investidor e assim sinalizar para o mercado a qualidade dos ativos é a retenção por parte da empresa de uma parcela destes ativos, neste caso a empresa acaba também participando do risco, e desta forma, o investidor se sente mais protegido da possibilidade de seleção adversa, já que a empresa originaria detém mais conhecimento do risco dos fluxos de caixa destes ativos.

A operação de securitização tem sido discutida em vários trabalhos. Valverde et al. (2015) pesquisaram sobre como o envolvimento dos bancos com a securitização impactam as restrições de financiamento de seus mutuários nos períodos de crise e nos períodos normais. Ayotte et al. (2011) estudaram as implicações decorrentes do afastamento do risco de falência proporcionado pela securitização de ativos.

Hollander et al. (2015) pesquisaram sobre o impacto dos anúncios de securitização no valor de mercado dos bancos envolvidos nas transações, desta maneira, afirmando que estes anúncios estão positivamente relacionados com o aumento da liquidez nos bancos e que os retornos estão negativamente relacionados com carteiras de alto risco.

Le et al. (2016) analisaram as mudanças no risco para os bancos com securitização após a crise de 2007, indicando que antes de 2007 a securitização possui a tendência de aumentar o risco, porém após a crise não encontraram os mesmos indícios, sugerindo que os bancos ficaram menos incentivados a se envolverem com riscos em operações de securitização.

Já se tratando de estudos que procuraram relacionar a utilização da securitização com o desempenho das firmas, pouco tem sido discutido. Goldberg (2011) estudou o impacto do anúncio securitização de ativos de empresas brasileiras, por meio de FIDC, no valor de suas ações, o autor aplicou o estudo em 38 emissões de FIDCs, no entanto não constatou influência destes anúncios no preço das ações.

Sardá et al. (2015) propuseram um modelo para o processo de securitização, procurando utilizar um nível ótimo, visando maximizar os resultados e diminuir o tempo de recuperação dos investimentos, segundo os autores, a utilização do modelo proporciona resultados positivos tanto para as empresas quanto para os investidores.

Riachi et al. (2015) através de seu estudo com empresas norte-americanas, considerando o período de 1992 a 2006, evidenciaram que a utilização de securitização está associada com aumento de investimento e melhora no desempenho em empresas com maior risco de dificuldade financeira, os autores, também propuseram que as empresas podem utilizar os recursos obtidos com securitização para recomprar ações e 
com isso sinalizar para o mercado uma melhora de sua expectativa de crescimento.

\section{Securitização no Brasil}

Fernandes et al. (2014) dizem que a securitização no Brasil é estruturada principalmente por meio de FIDCs, diferindo do processo de securitização tradicional na forma jurídica, porém mantendo as principais características. Segundo os autores, o aumento da utilização da securitização no Brasil, juntamente com problemas nas emissões de alguns bancos, fez com que o Banco Central ampliasse os mecanismos de controle, principalmente com a resolução 3.533 , que criou procedimentos na classificação, registro e divulgação de operações de negociação de ativos financeiros, e com a criação da Central de Cessão de Crédito.

A CVM (2001) define os FIDCs como "uma comunhão de recursos que destina parcela preponderante do respectivo patrimônio líquido para a aplicação em direitos creditórios". Segundo Luxo (2010) a utilização dos FIDCs, em vez do processo tradicional de securitização, acontece principalmente por causa dos custos relacionados. Segundo o autor, custos administrativos e custos fiscais são inferiores quando a empresa realiza a securitização por meio dos FIDCs.

Com relação aos tributos, em quanto a SPE é sujeita a PIS (Programa de Integração Social), COFINS (Contribuição para o Financiamento da Seguridade Social), IRPJ (Imposto de Renda Pessoa Jurídica) e CSLL (Contribuição Social sobre o Lucro Líquido), os FIDCs, que cumprem a mesma função e não possuem personalidade jurídica, não sofrem incidência destes tributos, com isso acabam se apresentando de forma muito mais vantajosa para as empresas (ANBIMA, 2015). Fernandes et al. (2014) dizem que foram estas vantagens tributárias, obtidas pela utilização dos FIDCs, que proporcionaram um grande crescimento do financiamento das empresas por meio da securitização de ativos.

Pinheiro et al. (2009) dizem que os recursos obtidos com os FIDCs ocorrem "através da emissão de cotas que se subordinam entre si quanto ao pagamento para o investidor, denominadas cota sênior e cota subordinada". Estas cotas são valores mobiliários que representam "frações ideais do patrimônio do fundo" (FAVERO JÚNIOR, 2014).

A diferença entre os dois tipos de cotas é que a cota sênior tem prioridade no recebimento, ou seja, "o administrador do fundo, ao receber os pagamentos decorrentes das operações de crédito da carteira do fundo, amortiza e remunera a cota sênior em primeiro lugar; havendo recursos, ele irá amortizar e remunerar a cota subordinada" (PINHEIRO et al., 2009).

Normalmente uma parte ou a totalidade das cotas subordinadas é adquirida pela própria empresa cedente dos ativos, desta forma confere mais confiabilidade para o fundo, já que a empresa originaria passa participar dos riscos da carteira juntamente com os demais cotistas (ANBIMA, 2015). Pinheiro et al. (2009) dizem que a compra de cotas subordinadas por parte da empresa originária é uma forma de viabilizar o processo de securitização.

Outra característica que também traz segurança aos investidores de cotas dos FIDCs é a diversificação das carteiras, já que existi uma "vedação à aquisição de direitos creditórios e outros ativos de um mesmo 
devedor, ou de coobrigação de uma mesma pessoa ou entidade, além do limite de $20 \%$ (vinte por cento) de seu patrimônio líquido" (ANBIMA, 2015).

\section{MATERIAIS E MÉTODOS}

A pesquisa utilizou uma abordagem quantitativa, que faz uso da quantificação na coleta e no tratamento dos dados, lançando mão de técnicas estatísticas que buscam evitar distorções na interpretação e análise dos resultados, dando mais segurança às inferências realizadas e possibilitando a indicação de possíveis fatores causais que podem ser encontrados na comparação entre as variáveis estudadas (DIEHL et al., 2004).

A amostra foi composta por 15 empresas do setor de construção civil. Estas empresas possuem ativos negociados na B3 (bolsa de valores do Brasil) e participam do segmento de Novo Mercado. A seguir o Quadro 1 traz a relação das empresas.

Quadro 1: Empresas participantes da amostra.

\begin{tabular}{|l|l|}
\hline CR2 Empreendimentos Imobiliários S.A. & MRV Engenharia e Participações S.A. \\
\hline Cyrela Brazil Realty S.A.Empreend e Part. & PDG Realty S.A. Empreend e Participações \\
\hline Direcional Engenharia S.A. & Rodobens Negócios Imobiliários S.A. \\
\hline Even Construtora e Incorporadora S.A. & Rossi Residencial S.A. \\
\hline Ez Tec Empreend. E Participações S.A. & Tecnisa S.A. \\
\hline Gafisa S.A. & Trisul S.A. \\
\hline Helbor Empreendimentos S.A. & Viver Incorporadora e Construtora S.A. \\
\hline JHSF Participações S.A. & \\
\hline
\end{tabular}

Os dados financeiros analisados foram coletados junto ao Sistema Economatica ${ }^{\circ}$, menos os dados de valores de securitização, estes foram coletados nas notas explicativas das demonstrações financeiras padronizadas disponíveis nos sítios oficiais das empresas, após a coleta, todos dados foram exportados para planilhas eletrônicas do Microsoft Excel ${ }^{\circ}$ a fim de serem melhores tabulados e preparados para a exportação ao software Gretl versão 19.1, utilizado para analisar os resultados.

Cabe ressaltar que as empresas não divulgam de forma exata os valores obtidos através de processos de securitização, desta forma os valores foram encontrados mediante o cálculo da diferença entre o patrimônio líquido de todas as empresas as quais elas possuem investimentos e a participação relativa das empresas, ou seja, o quanto destes investimentos a empresa consegue transferir para terceiros.

Não foram encontradas as informações sobre os investimentos e as participações relativas da CR2 de 2007 a 2011, da Gafisa em 2007 e da PDG em 2007 e 2010, desta forma o nível de securitização para estas empresas nestes anos foi considerado zero.

Os indicadores utilizados com o objetivo de identificar as influências da securitização no desempenho das empresas podem ser vistos no Quadro 2.

A pesquisa foi realizada com a utilização da técnica de análise de regressão com dados em painel, técnica que possibilita o estudo de variáveis combinando séries temporais com cortes transversais. Segundo McClave et al. (2009) a maioria das pesquisas que fazem uso da análise de regressão utilizam modelos mais complexos que modelos de linha reta. Para Carvalho et al. (2014) "a modelagem por painel possibilita ampliar 
consideravelmente o número de observações da amostra e introduz maior variabilidade aos dados".

Quadro 2: Indicadores utilizados na análise.

\begin{tabular}{|c|c|c|}
\hline Indicador & Fórmula & Definição \\
\hline 1 - Liquidez Corrente (LC) & $\frac{\text { Ativo Circulante }}{\text { Passivo Circulante }}$ & $\begin{array}{l}\text { Capacidade das empresas em pagarem suas dívidas de curto } \\
\text { prazo. }\end{array}$ \\
\hline 2 - Nível de Endividamento (NE) & $\frac{\text { Exigível Total }}{\text { Patrimônio Líquido }}$ & Proporção da dívida total em relação aos recursos próprios. \\
\hline $\begin{array}{l}3 \text { - Retorno sobre o } \\
\text { investimento (ROI) }\end{array}$ & $\frac{\text { Lucro Operacional Líquido }}{\text { Investimento }}$ & $\begin{array}{l}\text { Retorno do investimento, independente da fonte de } \\
\text { financiamento. }\end{array}$ \\
\hline $\begin{array}{l}4 \text { - Retorno sobre capital } \\
\text { próprio (ROE) }\end{array}$ & $\frac{\text { Lucro Líquido }}{\text { Patrimônio Líquido }}$ & $\begin{array}{l}\text { Retorno do investimento realizado através de recursos } \\
\text { próprios. }\end{array}$ \\
\hline 5 - Custo da dívida $(\mathrm{Kd})$ & $\frac{\text { Despesas Financeiras }}{\text { Dívida Total }}$ & $\begin{array}{l}\text { Custo de captação para os recursos adquiridos junto a } \\
\text { terceiros. }\end{array}$ \\
\hline 6 - Margem Líquida (ML) & $\frac{\text { Lucro Líquido }}{\text { Receita Líquida }}$ & Parcela da receita que a empresa consegue reter. \\
\hline 7 - Lucro por Ação (LPA) & $\frac{\text { Lucro Líquido }}{\text { Número de Ações }}$ & Proporção de lucro gerado por ação. \\
\hline 8 - Preço/Lucro (P/L) & $\frac{\text { Preço de mercado da ação }}{\text { LPA }}$ & Relação do preço da ação com seu lucro gerado. \\
\hline $\begin{array}{l}9 \text { - Retorno médio da Ação ( } \mathrm{R}_{\mathrm{i}} \\
\text { ) }\end{array}$ & $\begin{array}{l}\text { Média dos Retornos da } \\
\text { Ação }\end{array}$ & Médias de retornos gerados pelas negociações da ação. \\
\hline $10-$ Beta & $\frac{\operatorname{COV}_{\mathrm{m}, \mathrm{i}}}{\operatorname{VAR}_{\mathrm{R}_{\mathrm{M}}}}$ & Parcela de risco sistemático assumido pela empresa. \\
\hline 11 - Ativo Total (AT) & Valor total do Ativo & Tamanho da empresa com relação ao valor total de seus ativos. \\
\hline 12 - Nível de Securitização (NS) & $\frac{\text { Volume de Securitização }}{\text { DívidaTotal }}$ & $\begin{array}{l}\text { Representatividade do volume de securitização em } \\
\text { comparação da dívida total. }\end{array}$ \\
\hline
\end{tabular}

Ainda sobre dados em painel, Stock et al. (2004) dizem que "consistem de observações das mesmas $n$ entidades para dois ou mais períodos de tempo $T^{\prime \prime}$. Para Stock et al. (2004) o estudo das variações possibilita a eliminação de possíveis efeitos de variáveis que diferem nas entidades e além de serem constantes, ao longo do período estudado, podem estar omitidas.

O estudo abordou um período de 9 anos (2007 a 2015), a escolha do setor ocorreu por, além de ser relevante para economia no Brasil, ser um dos principais setores na utilização de instrumentos de securitização.

\section{RESULTADOS E DISCUSSÃO}

Esta seção destina-se a apresentação e discussão dos resultados. A Tabela 1 traz algumas estatísticas descritivas de todas as variáveis utilizadas no modelo.

Tabela 1: Estatísticas Descritivas.

\begin{tabular}{lllllll}
\hline Variável & Média & Mediana & Mínimo & Máximo & Desv. Padrão & C.V. \\
\hline LC & 2,73627 & 2,41150 & 0,701489 & 11,5156 & 1,32931 & 0,485811 \\
\hline $\mathrm{NE}$ & 147,523 & 128,706 & $-807,595$ & 1778,93 & 182,892 & 1,23975 \\
\hline $\mathrm{ROI}$ & 3,78713 & 4,82986 & $-21,6784$ & 16,5522 & 5,65255 & 1,49257 \\
\hline $\mathrm{ROE}$ & 3,25428 & 9,87972 & $-286,276$ & 27,8969 & 32,2090 & 9,89744 \\
\hline $\mathrm{Kd}$ & 0,142773 & 0,0557211 & 0,00000 & 5,77993 & 0,550685 & 3,85707 \\
\hline $\mathrm{ML}$ & 1,76454 & 11,3793 & $-233,584$ & 54,5789 & 40,5370 & 22,9731 \\
\hline $\mathrm{LPA}$ & $-4,00872$ & 0,780781 & $-155,852$ & 40,9302 & 24,0756 & 6,00580 \\
\hline $\mathrm{P} / \mathrm{L}$ & 6,10678 & 8,05051 & $-417,310$ & 99,0258 & 41,4215 & 6,78288 \\
\hline $\mathrm{R}_{\mathrm{i}}$ & 9,80897 & $-12,8820$ & $-95,8234$ & 514,106 & 94,6793 & 9,65232 \\
\hline
\end{tabular}




\begin{tabular}{lllllll}
\hline BETA & 1,03877 & 0,913761 & $-0,542108$ & 3,65893 & 0,809575 & 0,779362 \\
\hline NS & 0,694724 & 0,238422 & 0,00000 & 20,2588 & 2,13075 & 3,06704 \\
\hline AT & $4,30671 \mathrm{e}+006$ & $2,84940 \mathrm{e}+006$ & $2,2697 \mathrm{e}+005$ & $1,72531 \mathrm{e}+007$ & $4,13174 \mathrm{e}+006$ & 0,959374 \\
\hline
\end{tabular}

Apesar destas estatísticas se referirem aos indicadores de empresas do mesmo setor, pode ser percebido uma grande variabilidade dos resultados para as mesmas variáveis. Nota-se que exceto a LC, o Beta e o AT todas as variáveis apresentaram Coeficiente de Variação (CV) maior que um, denotando que o desvio padrão é superior à média. A elevada dispersão dos resultados corrobora a importância da análise ao nível da firma e não do setor, pois este, enquanto valor médio, não representa o comportamento da amostra, tendo em vista, a importância do papel da administração das empresas nas estratégias financeiras de cada empresa.

O NE, desconsiderando o AT, foi o que apresentou o maior desvio padrão, denotando a grande diferença do perfil de endividamento das empresas, o que implica diretamente em adoção de diferentes estratégias na gestão de suas estruturas de capital. O ROI, ROE e ML, que são os indicadores de rentabilidade e lucratividade, também apresentaram grande variabilidade, ou seja, enquanto algumas empresas conseguem operar com altos níveis de rentabilidade, outras operam com rentabilidade negativa. Esta dispersão pode ser percebida levando em conta a distância de um desvio padrão da média, que abrange observações do ROI com índices entre -1,87 a 9,44, do ROE entre -28,95 a 35,46 e da ML entre -38,77 e 42,30. A maior variabilidade do ROE em comparação ao ROI denota o efeito da alavancagem dos diferentes perfis de endividamento das empresas.

O Kd é a variável de menor desvio padrão, já sobre os indicadores relacionados com as ações, que são o LPA, o P/L, o $R_{\mathrm{i}}$ e o Beta, assim como os indicadores de rentabilidade, apresentarem grande dispersão, com destaque para o $R_{i}$, que possui uma concentração entre $-84,87$ a 104,49 , levando em conta as observações com diferença de um desvio padrão da média. Sobre o NS, em comparação com o NE, apresentou dentro da amostra uma dispersão muito menor, tendo índices de mínimo 0 e máximo 20,26, e com um desvio padrão de 2,13. A Tabela 2 traz a matriz de correlação destas variáveis.

Tabela 2: Matriz de correlação.

\begin{tabular}{|c|c|c|c|c|c|c|c|c|c|c|c|c|}
\hline $\begin{array}{l}\text { LC } \\
1,0000 \\
\end{array}$ & NE & $\mathrm{ROI}$ & ROE & $\mathrm{Kd}$ & $\mathrm{ML}$ & LPA & $\mathrm{P} / \mathrm{L}$ & $\mathrm{Ri}$ & BETA & NS & AT & \\
\hline \multirow[t]{12}{*}{1,0000} & $-0,2971$ & 0,1517 & 0,2287 & 0,2060 & 0,2025 & 0,2277 & 0,0309 & $-0,0045$ & $-0,2334$ & 0,3631 & $-0,2873$ & $\mathrm{LC}$ \\
\hline & 1,0000 & $-0,2321$ & $-0,7499$ & $-0,0698$ & $-0,1538$ & $-0,2447$ & $-0,1270$ & $-0,0292$ & 0,0096 & $-0,1418$ & 0,1044 & $\mathrm{NE}$ \\
\hline & & 1,0000 & 0,6683 & $-0,1195$ & 0,7930 & 0,6125 & 0,1734 & 0,3110 & $-0,1174$ & 0,0018 & $-0,0612$ & $\mathrm{ROI}$ \\
\hline & & & 1,0000 & $-0,0525$ & 0,6564 & 0,6096 & 0,0755 & 0,2156 & $-0,0903$ & 0,0308 & $-0,0186$ & ROE \\
\hline & & & & 1,0000 & $-0,1123$ & $-0,0830$ & $-0,0256$ & $-0,0178$ & $-0,1248$ & 0,9282 & $-0,1185$ & $\mathrm{Kd}$ \\
\hline & & & & & 1,0000 & 0,6458 & 0,1016 & 0,2234 & $-0,0668$ & $-0,0305$ & 0,0165 & $\mathrm{ML}$ \\
\hline & & & & & & 1,0000 & 0,0832 & 0,2352 & $-0,0737$ & 0,0204 & 0,0075 & LPA \\
\hline & & & & & & & 1,0000 & $-0,3405$ & 0,0379 & 0,0596 & 0,0361 & $\mathrm{P} / \mathrm{L}$ \\
\hline & & & & & & & & 1,0000 & 0,0862 & $-0,0295$ & $-0,1384$ & $\mathrm{Ri}$ \\
\hline & & & & & & & & & 1,0000 & $-0,1500$ & 0,3372 & BETA \\
\hline & & & & & & & & & & 1,0000 & $-0,1492$ & NS \\
\hline & & & & & & & & & & & 1,0000 & AT \\
\hline
\end{tabular}

O Kd e o NS foram as variáveis que apresentaram a maior correlação. Isso pode ser explicado pelo fato de empresas com alto custo de dívida tendem a procurar outros meios para financiar suas atividades, com isso acabam encontrando na securitização de ativos uma melhor opção para o levantamento de 
recursos.

A busca, por parte das empresas, para financiar suas atividades a um custo menor é um dos fatores apontados por Luxo (2010) como motivador para a utilização da securitização, desta forma, segundo Campbell et al. (2011) utilizam ativos que possuem um rating de crédito melhor do que o da própria empresa para lastrear os títulos que são emitidos e negociados no mercado.

A LC também apresentou uma correlação positiva com NS, indicando que a securitização poderia contribui para o aumento de liquidez da empresa, entretanto o coeficiente de correlação de apenas 0,3631 não traz forte indício para esta associação.

Desta forma, após serem testadas todas as variáveis levantadas neste estudo, foi construído o modelo de regressão com dados em painel com as principais variáveis que trazem impacto nas estratégias de securitização, como pode ser visto na Tabela 3, que traz o NS com variável dependente.

Os resultados expressos na Tabela 3 foram alcançados utilizando o método de mínimos quadrados ponderados, tendo em vista, que quando aplicado o método com efeitos fixos verificou-se a presença de heteroscedasticidade e autocorrelação dos resíduos. A presença destes fatores restritivos à análise de regressão é comum quando aplicado à realidade empresarial (HAIR JUNIOR et al., 2005). Por isso, utilizou-se o método com efeitos ponderados para solucionar tais limitações.

Tabela 3: Modelo de regressão com dados em painel (variável dependente NS).

\begin{tabular}{|c|c|c|c|c|c|}
\hline \multicolumn{6}{|c|}{ Pesos baseados nas variâncias de erro por unidade } \\
\hline & Coeficiente & Erro Padrão & razão-t & p-valor & \\
\hline Const & $-0,152619$ & 0,175992 & $-0,8672$ & 0,3875 & \\
\hline $\mathrm{NE}$ & $-0,000906048$ & 0,000409181 & $-2,2143$ & 0,0286 & $* *$ \\
\hline $\mathrm{Kd}$ & 3,34903 & 0,151405 & 22,1196 & $<0,0001$ & $* * *$ \\
\hline ROI & 0,0168422 & 0,00786 & 2,1428 & 0,0340 & $* *$ \\
\hline LC & 0,155891 & 0,044805 & 3,4793 & 0,0007 & $* * *$ \\
\hline BETA & $-0,0762474$ & 0,0439426 & $-1,7352$ & 0,0851 & $*$ \\
\hline AT & 1,54113e-08 & 7,69905e-09 & 2,0017 & 0,0474 & $* *$ \\
\hline \multicolumn{6}{|c|}{ Estatísticas baseadas nos dados ponderados: } \\
\hline \multicolumn{2}{|c|}{ Soma resíd. Quadrados } & 119,6047 & E.P. da regressão & \multicolumn{2}{|l|}{0,966650} \\
\hline \multicolumn{2}{|c|}{ R-quadrado } & 0,814533 & R-quadrado ajustado & \multicolumn{2}{|l|}{0,805839} \\
\hline \multicolumn{2}{|c|}{$F(6,128)$} & 93,69170 & P-valor(F) & \multicolumn{2}{|l|}{$2,12 \mathrm{e}-44$} \\
\hline \multicolumn{2}{|c|}{ Log da verossimilhança } & $-183,3836$ & Critério de Akaike & \multicolumn{2}{|l|}{380,7673} \\
\hline \multicolumn{2}{|c|}{ Critério de Schwarz } & 401,1042 & Critério Hannan-Quinn & \multicolumn{2}{|l|}{389,0316} \\
\hline \multicolumn{6}{|c|}{ Estatísticas baseadas nos dados originais: } \\
\hline \multicolumn{2}{|c|}{ Média var. dependente } & 0,694724 & D.P. var. dependente & \multicolumn{2}{|l|}{2,130750} \\
\hline \multicolumn{2}{|c|}{ Soma resíd. Quadrados } & 67,06598 & E.P. da regressão & \multicolumn{2}{|l|}{0,723846} \\
\hline
\end{tabular}

Os intervalos de confiança dos estimadores do modelo são apresentados na Tabela 4.

Tabela 4: Intervalo de confiança do modelo.

$\mathrm{t}(128,0,025)=1,979$

\begin{tabular}{lll}
\hline Variável & Coeficiente & Intervalo de confiança de 95 \\
\hline Const & $-0,152619$ & $(-0,500850,0,195611)$ \\
\hline NE & $-0,000906048$ & $(-0,00171568,-9,64135 \mathrm{e}-005)$ \\
\hline Kd & 3,34903 & $(3,04945,3,64861)$ \\
\hline ROI & 0,0168422 & $(0,00128985,0,0323945)$ \\
\hline LC & 0,155891 & $(0,0672369,0,244546)$ \\
\hline BETA & $-0,0762474$ & $(-0,163195,0,0107005)$ \\
\hline AT & $1,54113 \mathrm{e}-008$ & $(1,77424 \mathrm{e}-010,3,06452 \mathrm{e}-008)$
\end{tabular}

O índice de determinação apresentado foi relevante, indicando que o NS das empresas estudadas 
pode ser explicado em $81,45 \%$ com as variáveis deste modelo, ressalta-se que a constante não foi significativa e o $R^{2}$ ajustado é muito próximo do coeficiente de determinação. Não obstante, a estatística $F$ do modelo rejeita a hipótese nula de má especificação do modelo quanto ao uso das variáveis explicativas.

Como também pode ser percebido na matriz de correlação, o Kd é a variável com mais impacto no NS, reforçando a hipótese de que o custo da dívida traz impacto nas estratégias de securitização, já que segundo o modelo, a variação de $1 \%$ no Kd traz uma variação de $3,35 \%$ no NS e a variável apresenta significância maior que 99\%.

Com relação aos outros indicadores, eles também apresentaram influência significativa, ainda que o coeficiente seja inferior, no entanto, a análise de confiança dos estimadores denota que os intervalos de 95\% dos coeficientes reportam para a mesma direção e a amplitude é pequena, o que aumenta a confiabilidade das estimativas para análise.

Verifica-se que o Beta e o NE apresentam coeficientes negativos, isto é, quanto maior o nível de endividamento e risco sistemático da empresa menor é o seu nível de securitização. Essa evidência sugere que empresas nessa situação podem apresentar dificuldades em securitizar seus ativos no mercado, seja pelo prêmio a ser pago no deságio dos títulos ou mesmo pela demanda por esses papéis. Uma vez que a empresa supre de forma mais intensa sua necessidade de financiamento com dívidas, em vez de utilizar a securitização, ela deixa de realizar a dispersão dos riscos de seus ativos, assim ficando mais exposta aos riscos sistemáticos inerentes aos mesmos (SILVESTRINI et al., 2011; FARIA, 2011; LE et al., 2016).

Por outro lado, este resultado demonstra a importância da diversificação das fontes de financiamento, pois a não utilização de estratégias de securitização no portfólio de investimentos da empresa pode pressionar a elevação do endividamento, cuja reversão pode trazer dificuldades às empresas, deste modo, empresas com menor NS, tendem a ter uma base de fontes de financiamento com uma diversificação mais reduzida (LUXO, 2010) e ficam mais expostas a riscos (LE et al., 2016).

A liquidez corrente e o ROI exerceram influência significativa e positiva no nível de securitização o que corrobora a importância de pressupostos financeiros sólidos da empresa para utilizar a estratégia de securitização. Ainda, a variável Tamanho (Ativo total) mostrou-se significativa e positiva para explicar o nível se securitização o que relata tanto a necessidade de diversificar as fontes de capital para viabilizar os investimentos como também a importância do lastro institucional nas empresas como garantia para o mercado.

Já considerando a análise sobre a influência da securitização no desempenho das empresas do setor de construção civil, o único modelo que apresentou significância foi o $P / L$, enquanto medida de criação de valor, como apresentado na Tabela 5 . O intervalo de confiança da influência do NS no P/L é visto na Tabela 6.

Nota-se efeito positivo e significativo do NS no P/L. Essa influência significa que a securitização é uma estratégia de criação de valor, pois contribui para o aumento na relação $\mathrm{P} / \mathrm{L}$ o que pode estar associado com a redução do risco e a maior capacidade de investimento da empresa. Segundo Gitman (2010) "o índice P/L mede o montante que os investidores estão dispostos a pagar por unidade monetária de lucro de uma 
empresa", desta forma, segundo o autor, demonstrando o nível de confiança que é depositado na empresa pelos investidores com relação ao seu desempenho futuro. Desta maneira, as estratégias de securitização são entendidas pelo mercado como estratégias financeiras com potencial de criação de valor.

Tabela 5: Modelo de regressão com dados em painel para a Influência do NS no P/L. Pesos baseados nas variâncias de erro por unidade

\begin{tabular}{llllll}
\hline & Coeficiente & Erro Padrão & razão-t & p-valor \\
\hline Const & 7,63011 & 0,799632 & 9,5420 & $<0,0001$ & $* * *$ \\
\hline NS & 0,729325 & 0,156976 & 4,6461 & $<0,0001$ & $* * *$ \\
\hline
\end{tabular}

Estatísticas baseadas nos dados ponderados:

\begin{tabular}{llll}
\hline Soma resíd. Quadrados & 124,5798 & E.P. da regressão & 0,967828 \\
\hline R-quadrado & 0,139639 & R-quadrado ajustado & 0,133170 \\
\hline $\mathrm{F}(1,133)$ & 21,58618 & P-valor(F) & $8,04 \mathrm{e}-06$ \\
\hline Log da verossimilhança & $-186,1345$ & Critério de Akaike & 376,2691 \\
\hline Critério de Schwarz & 382,0796 & Critério Hannan-Quinn & 378,6303 \\
\hline Estatísticas baseadas nos dados originais: & & & \\
\hline Média var. dependente & 6,106780 & D.P. var. dependente & 41,42154 \\
\hline Soma resíd. Quadrados & 229761,9 & E.P. da regressão & 41,56360 \\
\hline
\end{tabular}

Nota: $* * *>99 \%$ de significância.

Tabela 6: Intervalo de confiança (influência do NS no $P / L$ ). $\mathrm{t}(133,0,025)=1,978$

\begin{tabular}{lll}
\hline Variável & Coeficiente & Intervalo de confiança de 95 \\
\hline Const & 7,63011 & $(6,04847,9,21175)$ \\
\hline NS & 0,729325 & $(0,418832,1,03982)$ \\
\hline
\end{tabular}

Essa constatação corrobora os determinantes do NS apontados na Tabela 4, pois observou-se que o NS é influenciado por empresas com liquidez, rentabilidade, baixo endividamento e risco sistemático, além de se apresentar como estratégia para reduzir o custo de captação de recursos junto a terceiros; logo, o NS demonstra para empresas deste setor como uma estratégia que possibilita a maximização da riqueza por meio de fundamentos financeiros sólidos.

Como ocorre uma transferência de risco dos ativos que são securitizados pelas empresas (SILVESTRINI et al., 2011; LE et al., 2016), a seleção destes ativos é um fator de extrema relevância, já que uma vez que a empresa reduz sua participação no risco destes ativos, pode conseguir uma melhora na avaliação de seus papéis. Levando isso em consideração, estratégias que venham otimizar o processo de escolha dos ativos que serão securitizados, trará benefícios para empresa, podendo através desta seleção ampliar a confiança dos investidores com relação ao seu futuro.

Em tempo, uma vez que a empresa transfere riscos de seus ativos para outros agentes, estes também passam a ser diretamente interessados no desempenho destes ativos, o que pode ser um fator que incentive a empresa a ter ainda mais atenção na qualidade de seus ativos, já que eles serão avaliados por um número maior de agentes.

Já com relação à retenção de parte dos ativos, visando à participação do risco e consecutivamente a transmissão de maior transparência para os investidores dos títulos (FAVERO JÚNIOR, 2014), deve ser também pensada de forma estratégica pela empresa, já que ela deverá levar em conta não somente aos investidores dos títulos securitizados, mas também aos seus atuais e futuros acionistas, uma vez que a retenção dos riscos influenciará em sua avaliação perante o mercado.

Não obstante, empresas com elevado P/L são empresas muito bem avaliadas, cuja demanda pela 
compra dos seus papeis é maior que a oferta de venda, no entanto isso pode gerar uma bolha especulativa, isto é, o preço das ações pode assumir um valor superior ao seu valor intrínseco motivado por uma maior expectativa por resultados futuros dos acionistas frente à própria capacidade da empresa em gerar tais resultados (DRESCHER et al., 2016). Essa possibilidade decorre das assimetrias de informações entre os administradores e acionistas, cujo processo de securitização pode potencializar, em especial, por disponibilizar no caixa das empresas os recursos securitizados (BRANCH, 2016). Assim, há a necessidade de maior esforço de governança e controle desse processo.

Desta forma, torna-se necessário uma atuação eficiente não só da empresa, mas de todos os agentes envolvidos no processo de securitização, uma vez que a transparência deste processo irá trazer uma melhora na comunicação com o mercado, e consecutivamente na expectativa futura do desempenho da empresa, de modo que o valor intrínseco da empresa represente as expectativas de longo prazo dos stakeholders.

\section{CONCLUSÕES}

O objetivo deste trabalho foi analisar os determinantes das estratégias de securitização utilizadas pelas empresas do setor de construção civil e os impactos no seu desempenho econômico e financeiro. Diante dos resultados apontados, verificou-se que o NE, o Kd, o ROI, a LC, o Beta e o AT são as principais variáveis determinantes do NS, e que o único indicador de desempenho que sofre influência do NS é o P/L.

De todas as variáveis estudadas, o Kd foi o que teve maior associação com o NS, indicando que empresas que possuem maior custo para obterem financiamento através de dívidas, tendem a fazer mais uso da securitização para levantar recursos visando financiar suas atividades. Este resultado vai ao encontro do apontado por diversos autores (LUXO, 2010; CAMPBELL et al., 2011; FERNANDES et al., 2014; PINHEIRO et al., 2009; FAVERO JÚNIOR, 2014).

Com relação às outras variáveis, embora sejam de menor impacto, devido aos coeficientes apresentados, possuem significância dentro do modelo, e com isso devem ser consideradas dentro do processo de securitização. Para o NE e o Beta, o resultado encontrado foi que exercem influência negativa no NS, desta maneira o maior endividamento e a maior exposição no risco sistemático podem fazer com que as empresas, que apresentem este quadro, encontrem maior dificuldade para explorar a securitização de seus ativos, o que traz menor diversificação na estrutura de financiamento destas empresas.

Já a LC e o ROI impactam positivamente no NS, denotando que empresas com maior liquidez e melhor rentabilidade conseguem captar mais recursos através da securitização de seus ativos, ou seja, fundamentos mais sólidos contribuem para este tipo estratégia, já que estes pressupostos convergem para uma melhor avaliação das empresas e consecutivamente de seus ativos, fazendo com que os títulos securitizados tenham uma maior demanda, principalmente devido à qualidade de seu lastro.

A variável AT também apresentou coeficiente positivo, o que pode levar a interpretação de que empresas de tamanho maior possuem mais necessidade de utilizar diferentes fontes de recursos dentro de sua estrutura de financiamento, e que além disso podem ter maior capacidade de reter parte dos riscos dos ativos que são ofertados no processo de securitização, e assim reforçando as garantias que são transmitidas 
para os investidores.

Sobre o impacto das estratégias de securitização no desempenho das empresas, o fato do NS influenciar no $\mathrm{P} / \mathrm{L}$, indica que o processo de securitização pode ser utilizado como ferramenta visando à valorização da empresa perante o mercado, uma vez que a empresa consegue gerir de forma mais adequada o risco de seus ativos, e atrair um número maior de agentes interessados em seus investimentos.

Desta forma, além de ser uma opção para busca de recursos financeiros a um custo menor, a securitização pode trazer outros benefícios, contribuindo para uma avaliação mais apurada dos ativos e para um aumento na confiança do mercado sobre a expectativa dos resultados futuros da empresa.

Os resultados alcançados neste trabalho fornecem uma melhor compreensão das variáveis que determinam as estratégias de securitização, assim como permitem a identificação dos possíveis efeitos causados por estas estratégias no desempenho das empresas. Portanto, este estudo traz implicações positivas acerca da utilização do processo de securitização por parte das empresas do setor de construção civil.

Considerando o pequeno número de estudos que buscaram associar a securitização com o desempenho empresarial, este trabalho contribui para o entendimento da relação destas duas variáveis, diante disso, reforçando uma reflexão acerca dos resultados que podem ser obtidos quando as empresas decidem dar maior ênfase na securitização dentro de suas estratégias financeiras. Entretanto, para reforçar esta associação, é necessário que novos estudos sejam realizados, já que este trabalho abordou apenas um setor da economia brasileira, também é relevante que novas metodologias sejam aplicadas a fim de intensificar a discussão sobre o tema.

Através do processo de levantamento dos dados, verificou-se a falta de importância dada pelas empresas do setor de construção civil na divulgação de informações referentes à securitização de seus ativos, já que não trazem de forma clara e objetiva os valores obtidos através deste instrumento em suas demonstrações financeiras. Levando em conta a relevância destas informações, seria plausível que as empresas refletissem sobre esta questão, já que se trata de um componente de sua gestão financeira, sendo um importante instrumento na busca de recursos para suprir suas necessidades de financiamento.

Diante deste quadro, o levantamento dos dados de securitização pode ser considerado uma limitação, já que foi necessário realizar o cálculo da diferença entre o patrimônio líquido de todas as empresas as quais possuem investimentos e as participações relativas para se chegar a uma proxy do valor de securitização.

Para trabalhos futuros, sugere-se que sejam realizados estudos semelhantes a este, com empresas de outros setores da economia brasileira, a fim de se verificar se existem diferentes determinantes nas estratégias de securitização e diferentes impactos destas estratégias em seus desempenhos econômico e financeiro. 


\section{REFERÊNCIAS}

ANBIMA. Associação Brasileira das Entidades dos Mercados Financeiro e de Capitais. Fundo de investimento em direitos creditórios. Rio de Janeiro: ANBIMA, 2015.

ANBIMA. Associação Brasileira das Entidades dos Mercados Financeiro e de Capitais. Boletim ANBIMA. ANBIMA, 2017.

ASSIS, J. S.; PEREIRA, M. A.; SANTOS, J. O.; GODOI, A. F.; ESOTICO, J. O.. Impacto da estrutura de capital no EVA ${ }^{\circledR}$ dos bancos listados na BM\&F BOVESPA. Revista Brasileira de Administração Científica, v.49, n.67, p.49-67, 2016. DOI: http://doi.org/10.6008/SPC2179-684X.2016.002.0004

AYOTTE, K.; GAON, S.. Asset-backed securities: Costs and benefits of "bankruptcy remoteness". Review of Financial Studies, v.24, n.4, p.1299-1336, abr 2011. DOI: http://doi.org/10.1093/rfs/hhq059

BRANCH, W. A. Imperfect knowledge, liquidity and bubbles. Journal of Economic Dynamics and Control, v.62, p.17-42, 2016.

BRITO, R. P.; BRITO, L. A. L.. Vantagem Competitiva, Criação de valor e seus efeitos sobre o Desempenho. Revista de Administração de Empresas, São Paulo, v.52, n.1, p.70-84, 2012.

CAMPBELL, S.; COVITZ, D.; NELSON, W.; PENCE, K.. Securitization markets and central banking: An evaluation of the term asset-backed securities loan facility. Journal of Monetary Economics, v.58, n.5, p.518-531, 2011. DOI: http://doi.org/10.1016/j.jmoneco.2011.05.003

CARVALHO, J.; DIVINO, J. A.; ORRILLO, J.. Determinantes do requerimento de colateral em empréstimos empresariais. Revista Brasileira de Economia, Rio de Janeiro, v.68, n.1, p.5-18, 2014. DOI: http://doi.org/10.1590/S0034$\underline{71402014000100002}$

CORREA, C. A.; BASSO, L. F. C.; NAKAMURA, W. T.. A estrutura de capital das maiores empresas brasileiras: análise empírica das teorias de pecking order e trade-off, usando panel data. Revista de Administração Mackenzie, São Paulo, v.14, n.4, p.106-133, 2013. DOI: http://doi.org/10.1590/S1678-69712013000400005

COSTA, D. M.. Revisitando os clássicos da moderna teoria de finanças: uma análise. Revista Brasileira de Administração Científica, v.8, n.2, p.16-41, 2017. DOI: https://doi.org/10.6008/SPC2179-684X.2017.002.0002

CUTLER, T.. Performance management in public services 'before' new public management: The case of nhs acute hospitals 1948-1962. Public Policy and Administration, v.26, n.1, p.129-147, 2011. DOI: http://doi.org/10.1177/0952076710375785

CVM. Comissão de Valores Mobiliários. Instrução CVM n.356, de 17 de dezembro de 2001. CMV, 2001.

DIEHL, A. A.; TATIM, D. C.. Pesquisa em ciências sociais aplicadas: métodos e técnicas. São Paulo: Prentice Hall, 2004.
DRESCHER, C.; HERZ, B.. What determines simultaneous asset bubbles? An empirical analysis. Applied Economics, v.48, n.1, p.35-51, 2016.

FABOZZI, F. J.; KOTHARI, V.. Securitization: the tool of financial transformation.Yale ICF Working Paper, n.07-07, 2007.

FAMÁ, R.; GRAVA, J. W.. Teoria da estrutura de capital: as discussões persistem. Caderno de pesquisas em administração, São Paulo, v.1, n.11, p.27-36, 2000.

FARIA, A. P.. Securitização imobiliária: uma opção de funding para o financiamento habitacional. Dissertação (Mestrado) - Escola Superior de Agricultura "Luiz de Queiroz", Piracicaba, 2011.

FAVERO JÚNIOR, O. Z.. Securitização de ativos e transferência de risco: evidências do mercado de capitais brasileiro. Dissertação (Mestrado em Controladoria e Contabilidade) - Universidade de São Paulo, São Paulo, 2014.

FERNANDES, M. P.; SHENG, H. H.; LORA, M. I.. Securitização, Rating de Crédito e Características dos Emissores. Brazilian Business Review, Vitória, v.11, n.6, p.1-22, 2014. DOI: http://doi.org/10.15728/bbr.2014.11.6.1

FERREIRA, F. A. F.; RODRIGUES, P. M. M.; SANTOS, S. P.; SPAHR, R.. How to create indices for bank branch financial performance measurement using MCDA techniques: an illustrative example. Journal of Business Economics and Management, v.15, n.4, p.708-728, 2014. DOI: http://doi.org/10.3846/16111699.2012.701230

GITMAN, L. J.. Princípios de administração financeira. 12 ed. São Paulo: Pearson Prentice Hall, 2010.

GOLDBERG, M. B.. A Securitização de recebíveis e seu impacto no valor das originadoras: evidências do mercado brasileiro. Dissertação (Mestrado) - Fundação Getúlio Vargas, São Paulo, 2011.

GUNDAY, G.; ULUSOY, G.; KILIC, K.; ALPKAN, L..Effects of innovation types on firm performance. International Journal of Production Economics, v.133, n.2, p.662-676, 2011. DOI: http://doi.org/10.1016/i.iipe.2011.05.014

HAIR JUNIOR, J. F.; BLACK, W. C.; BABIN, B. J.; ANDERSON, R. E.; TATHAM, R. L.; SANT'ANNA, M. A. G. A. S.. Análise multivariada de dados. 5 ed. Porto Alegre: Bookman, 2005.

HOLLANDER, H.; PROKOP, J.. Stock price effects of asset securitization: The case of liquidity facility providers. Quarterly Review of Economics and Finance, v.57, n.1, p.147-160, 2015. DOI: http://doi.org/10.1016/j.qref.2014.11.002

JENSEN, M.; MECKLING, W. H.. Theory of the firm: managerial behavior, agency costs and ownership structure. Journal of Financial Economics, p.305-360, 1976. DOI: http://doi.org/10.1016/0304-405X(76)90026-X

KANGARLOUEI, S. J.; AZIZI, A.; FARAHANI, M. S.; MOTAVASSEL, M.. The search for the best financial performance measure of companies listed in Tehran Stock 
Exchange (TSE). World Applied Sciences Journal, v.16, n.3, p.407-414, 2012

KUDLAWICZ, C.; SENFF, C. O.; BACH, T. M.. O desempenho econômico e a estrutura de capital: empresas brasileiras a luz da fronteira de eficiência. Journal Globalization, Competitiveness and Governability, p.40-52, 2015. DOI: http://doi.org/10.3232/GCG.2015.V9.N3.02

KUNDAKCHYAN, R. M.; ZULFAKAROVA, L. F.. Current issues of optimal capital structure based on forecasting financial performance of the company. Life Science Journal, v.11, n.6, p.368-371, 2014

LE, H. T. T.; NARAYANAN, R. P.; VAN VO, L.. Has the Effect of Asset Securitization on Bank Risk Taking Behavior Changed? Journal of Financial Services Research, v.49, n.1, p.39-64, fev 2016. DOI: http://doi.org/10.1007/s10693-015-0214-1

LUXO, J. C.. Estudo Comparativo dos Custos Operacionais e Tributários da Securitização e dos FIDCs. Revista de Finanças Aplicadas, v.1, p.1-12, 2010.

MATITZ, Q. R. S.; BULGACOV, S.. O Conceito Desempenho em Estudos Organizacionais e Estratégia: um Modelo de Análise Multidimensional. Revista de Administração Contemporânea, v.15, n.4, p.580-607, 2011.

MAZZI, C.. Family business and financial performance: Current state of knowledge and future research challenges. Journal of Family Business Strategy, v.2, n.3, p.166-181, 2011. DOI: http://doi.org/10.1016/j.jfbs.2011.07.001

MCCLAVE, J. T.; BENSON, P. G.; SINCICH, T.. Estatística para administração e economia. 10 ed. São Paulo: Pearson Prentice Hall, 2009.

MODIGLIANI, F.; MILLER, H. M.. The cost of capital, corporation finance and theory of investment. The American Economic Review, v.48, n.3, p.261-297, 1958.

MPUNDU, M.; PETERSEN, M. A.; MUKUDDEM-PETERSEN, J.; GIDEON, F.. Basel III and asset securitization.Dynamics in Nature and Society, p.1-19, 2013. DOI: http://doi.org/doi/10.1155/2013/439305

PINHEIRO, F. A. P.; SAVOIA, J. R. F.. Securitização de Recebíveis: Análise dos Riscos Inerentes. Revista Brasileira de Finanças, v.7, n.3, p.305326, 2009.
RIACHI, I.; SCHWIENBACHER, A.. Investment, firm performance and securitization: Evidence from industrial companies. Finance Research Letters, p.17-28, 2015. DOI: http://doi.org/10.1016/i.frl.2015.03.007

ROSS, S. A.. The determination of financial structure: the incentive-signaling approach. The Bell Journal of Economics, n.8, p.23-40, 1977.

SARDÁ, S.; MOLINA, M. C.. Optimization of securitized cash flows for toll roads. Advances in Intelligent Systems and Computing, v.377, p.393-405, 2015. DOI: http://doi.org/10.1007/978-3-319-19704-3 32

SILVESTRINI, A. D.; LIMA, R. A. S.. Securitização da Dívida Rural Brasileira: o caso do Banco do Brasil de 1995 a 2008. Revista de Economia e Sociologia Rural, Piracicaba, v.49, n.4, p.1021-1050, 2011. DOI: http://doi.org/10.1590/S010320032011000400009

STARLING, R. N.; PORTO, R. B.. Dinâmicas do desempenho financeiro, da mudança estratégica e da concentração industrial em empresas brasileiras. Revista de Administração Contemporânea, Rio de Janeiro, v.8, n.4, p.397-415, 2014. DOI: http://doi.org/10.1590/19827849rac20141049

STOCK, J. H.; WATSON, M. W.. Econometria. São Paulo: Addison Wesley, 2004.

VALVERDE, S. C.; DEGRYSE, H.; FERNÁNDEZ, F. R.. The impact of securitization on credit rationing: Empirical evidence. Journal of Financial Stability, v.20, p.36-50, 2015. ISSN DOI: http://doi.org/10.1016/i.jfs.2015.06.004

WÓJCIK, D.. Securitization and its footprint: The rise of the US securities industry centres 1998-2007. Journal of Economic Geography, v.11, n.6, p.925-947,2011. DOI: http://doi.org/10.1093/jeg/lbq045

YALCIN, N.; BAYRAKDAROGLU, A.; KAHRAMAN, C. Application of fuzzy multi-criteria decision making methods for financial performance evaluation of Turkish manufacturing industries. Expert Systems with Applications, v.39, n.1, p.350-364, 2012. DOI: http://doi.org/10.1016/j.eswa.2011.07.024

A CBPC - Companhia Brasileira de Produção Científica (CNPJ: 11.221.422/0001-03) detém os direitos materiais desta publicação. Os direitos referem-se à publicação do trabalho em qualquer parte do mundo, incluindo os direitos às renovações, expansões e disseminações da contribuiç̃o, bem como outros direitos subsidiários. Todos os trabalhos publicados eletronicamente poderão posteriormente ser publicados em coletâneas impressas sob coordenação da Sustenere Publishing, da Companhia Brasileira de Produção Científica e seus parceiros autorizados. Os (as) autores (as) preservam os direitos autorais, mas não têm permissão para a publicação da contribuição em outro meio, impresso ou digital, em português ou em tradução. 